CLINICAL STUDY

\title{
Long-term skeletal consequences of childhood acute lymphoblastic leukemia in adult males: a cohort study
}

\author{
O Mäkitie ${ }^{1,2}$, R Heikkinen ${ }^{3}$, S Toiviainen-Salo ${ }^{4}$, M Henriksson ${ }^{6}$, L-R Puukko-Viertomies ${ }^{3}$ and K Jahnukainen ${ }^{5}$ \\ ${ }^{1}$ Division of Pediatric Endocrinology and Metabolic Bone Diseases, Children's Hospital, Helsinki University Central Hospital, University of Helsinki, PO \\ Box 281, FIN-00029 Helsinki, Finland, ${ }^{2}$ Folkhälsan Research Center, Biomedicum Helsinki, Helsinki, Finland, ${ }^{3}$ Department of Adolescent Psychiatry, \\ Children's Hospital, Helsinki University Central Hospital, University of Helsinki, PO Box 281, FIN-00029 Helsinki, Finland, ${ }^{4}$ Helsinki Medical Imaging \\ Center, Helsinki University Central Hospital, Helsinki, Finland, ${ }^{5}$ Division of Hematology-Oncology and Stem Cell Transplantation, Children's Hospital, \\ Helsinki University Central Hospital, University of Helsinki, PO Box 281, FIN-00029 Helsinki, Finland and ${ }^{6}$ National Supervisory Authority for Welfare \\ and Health, Helsinki, Finland
}

(Correspondence should be addressed to O Mäkitie; Email: outi.makitie@helsinki.fi)

\begin{abstract}
Objective: Long-term health sequelae of childhood-onset acute lymphoblastic leukemia (ALL) remain largely unknown. Low bone mineral content (BMC) and bone mineral density (BMD) are recognized complications, but it is unknown whether these persist until adulthood. We evaluated skeletal characteristics and their association with ALL therapy in long-term male ALL survivors.

Design: This cross-sectional cohort study included 49 long-term male ALL survivors and 55 agematched healthy males.

Methods: BMD and compression fractures were assessed by dual-energy X-ray absorptiometry; blood biochemistry was obtained for parameters of calcium homeostasis.

Results: The ALL survivors (median age 29 years, range 25-38 years), assessed 10-38 years after ALL diagnosis, had lower lumbar spine $(P<0.001)$, femoral neck $(P<0.001)$, and whole-body $(P=0.017)$ BMD than expected based on normative values. When compared with the controls (median age 30 years, range 24-36 years), the ALL survivors had lower lumbar spine BMC $(P=0.014)$, lower whole-body BMC $(P<0.001)$, and lower whole-body BMD $(P<0.001)$, but the differences were partly explained by differences in height. Altogether, $20 \%$ of the ALL survivors had spinal compression fractures, but these were equally prevalent in the controls. Males diagnosed with ALL before age 5 years had significantly lower BMD values. Other recognized risk factors included untreated hypogonadism, vitamin D deficiency, hypophosphatemia, low IGF-binding protein-3, and low physical activity.

Conclusions: At young adulthood, long-term male ALL survivors have significantly reduced BMC and $\mathrm{BMD}$ and a high prevalence of spinal compression fractures. Careful follow-up and active treatment of the recognized risk factors are warranted.
\end{abstract}

European Journal of Endocrinology 168 281-288

\section{Introduction}

Treatment modalities of childhood cancer have significantly improved over the past decades. Consequently, an increasing number of cancer patients survive until adulthood. In the USA, the number of childhood cancer survivors was estimated to be more than 320000 , and $24 \%$ of them had survived over 30 years since diagnosis (1). With an increasing number of survivors, it has become important to evaluate long-term health consequences of childhood cancer. Studies show that, in young adulthood, a substantial proportion of childhood cancer survivors already has a high or severe burden of disease (2).

In acute lymphoblastic leukemia (ALL), the 5-year relative survival before 1970 was practically 0 , and a relatively small proportion of the ALL survivors are
30 years and older (1). The long-term health sequelae beyond early adulthood thus remain largely unknown. Previous studies have shown that among adult ALL survivors, hormonal deficiencies, hypogonadism, insulin resistance, and dyslipidemia are prevalent $(3,4$, $5,6)$. Low bone mineral density (BMD) and osteoporosis are also recognized complications of ALL, and according to some studies, adverse skeletal effects may persist until adulthood $(7,8,9,10,11,12)$.

Bone mass, the most important determinant of fracture risk (13), accrues with age, with peak attainment values occurring by early adulthood (14, 15). Therefore, peak bone mass may be significantly impacted by any disease process that reduces the rate and/or magnitude of skeletal mass accrual in childhood and adolescence (16). The first large cohort of childhood ALL survivors is now reaching its mid 30s. The aim of 
this study was to evaluate long-term skeletal effects of childhood ALL and treatment-related risk factors for impaired bone health in a large single-center cohort of male long-term survivors.

\section{Materials and methods}

\section{Study population}

Adult male long-term ( $>10$ years) ALL survivors who were born in 1980 or earlier and had been treated at Helsinki University Hospital in 1970-1998 were identified through hospital records and enrolled in the study assessing adult male health outcome of childhood ALL, as described previously (4). Among the total patient population of boys treated for ALL during the period $(n=164), 75$ male long-term survivors were identified and contacted. Altogether, 51 (68\%) consented and 24 subjects did not respond to the invitation. Based on hospital records, the clinical characteristics of the 24 nonresponders were comparable to those of the responders (data not shown). Control subjects (56 healthy males with no history of malignancy, aged between 24 and 36 years) were recruited from occupational health services of Helsinki municipality area and Helsinki University Central Hospital. All patients and control subjects were Caucasian males. The Research Ethics Committee of Helsinki University Hospital approved the study; an informed written consent was obtained from all study subjects.

\section{Study protocol}

Patients and controls were assessed similarly. The subjects were invited to participate in a study assessing reproductive health, related parameters, and overall well-being at adult age. Blood work relevant to testicular function and bone health was obtained, and BMD was measured with dual-energy X-ray absorptiometry (DXA). Bone densitometry was not obtained for two patients and one control subject and they were excluded from this study.

\section{Clinical characteristics}

Data on the patients' previous medical history, including cumulative doses of irradiation and cytotoxic drugs, were collected from hospital records. A detailed history of present health, ongoing endocrine replacement therapies, and other medications was obtained by patient interview and from hospital records. All the patients and controls were clinically assessed. Heights and weights were measured and values were compared with the Finnish norms and transformed to s.D. units (Z-scores) $(17,18)$. BMI was calculated as weight in kilograms divided by the square of height in meters $\left(\mathrm{kg} / \mathrm{m}^{2}\right)$. Information regarding physical activity (number of active training sessions per week) and TV and video watching (hours per day) was collected by interview.

\section{BMD measurements by DXA}

Bone mineral content (BMC) and areal BMD for the lumbar spines (L1-L4), femoral neck, total hip, and whole body were measured with DXA (Hologic Discovery A, Bedford, MA, USA, software version 12.3:3). The BMDs were transformed into Z- and T-scores using age-, sex-, and ethnicity-specific (USA White adults) reference data for the equipment. The Z-score is the number of s.D.s, a given BMD measurement differs from the mean for age- and sex-matched reference population. T-scores characterize BMD in comparison to young adults; WHO defines osteoporosis as a $T$-score $\leq-2.5$ and osteopenia as a T-score $>-2.5$ and $\leq-1.0$ (19). For this study, a cutoff Z-score value of -1.0 was chosen to define reduced $\mathrm{BMD}$. To minimize the effect of bone size on BMD, a mathematical model for correction of areal BMD for the anteroposterior depth of the vertebrae was used to obtain estimates of volumetric density and bone mineral apparent density (BMAD). BMAD was calculated with the formula BMAD $(\mathrm{L} 1-\mathrm{L} 4)=$ total BMC $(\mathrm{L} 1-\mathrm{L} 4) /($ area L1-L4) ${ }^{1.5}(20)$. Scans with foreign objects (e.g. surgical fixation material) or compressed lumbar vertebrae in the measurement area were omitted from the analysis. Consequently, lumbar spine scans of three patients and two controls and whole-body scans of three patients and two controls were excluded.

In order to detect vertebral compression fractures $(V F x)$, anteroposterior and lateral images of the thoracic and lumbar spine (Instant Vertebral Assessment (IVA)) were obtained for each subject using the DXA scanner. VFx were assessed according to the classification by Genant et al. (21). The IVA images were assessed independently by two experienced examiners (O Mäkitie and $\mathrm{S}$ Toiviainen-Salo). Discordant findings were reanalyzed for consensus. Borderline findings were classified as normal. The vertebrae were compared with adjacent vertebrae and graded depending on percent reduction in anterior, middle, or posterior vertebral height: below $20 \%$ as normal; $20-25 \%$, grade $1 ; 25-40 \%$, grade 2 ; and $\geq 40 \%$, grade 3 deformity (21).

\section{Biochemistry}

Blood samples were collected between 0800 and $1000 \mathrm{~h}$. Plasma calcium (Ca), phosphate $(\mathrm{Pi})$, and alkaline phosphatase (ALP) were measured using standard methods. Serum 25-hydroxyvitamin D (25-OHD) was assessed by liquid chromatography and plasma parathyroid hormone (PTH) by an immunoluminometric method. Serum FSH, LH, insulin-like growth factor 1 (IGF1), and IGF-binding protein-3 
(IGFBP3) were determined with time-resolved immunofluorometric assays and testosterone levels with liquid chromatography-mass spectrometry, estradiol levels with immunofluorometric assay, and inhibin-B by a specific two-sided enzyme immunometric assay in the laboratory of Helsinki University Central Hospital.

\section{Statistical analysis}

For areal BMD, T-scores were used only to determine the overall prevalence of osteopenia (a T-score between -1.0 and -2.5 ) and osteoporosis (a T-score at or below -2.5); Z-scores instead of T-scores were used in order to avoid confounding by age to determine the correlates of BMD. Simple regression analysis, Student's unpaired $t$-test (normally distributed variables), Mann-Whitney $U$ test (non-normally distributed variables), and $\chi^{2}$ test were used for statistical analysis, as appropriate, to determine the relationship between spinal changes, BMD, and specified clinical variables and to analyze differences in these parameters between subgroups. Differences between the groups were tested with multivariate analysis using relevant confounders in the models. Significance tests were two tailed. A $P$ value of $<0.05$ was considered statistically significant. The calculations were performed using PASW Statistics Software SPSS (version 19.0; SPSS, Inc., Chicago, IL, USA).

\section{Results}

\section{Cohort characteristics}

The 49 male ALL survivors were assessed at a median age of 29 years (range 25-38 years) and 10-38 years after the ALL diagnosis. Their median age at ALL diagnosis was 5 years; 15 patients $(31 \%)$ were older than 10 years at the end of ALL therapy. The median follow-up since end of ALL therapy was 20 years (10-29 years; Table 1). Seventy-three percent of the survivors had received cranial irradiation; 31 had received at least $24 \mathrm{~Gy}$, all of them before age 15 years. In addition, 35\% had received testicular irradiation and $49 \%$ cyclophosphamide as part of their ALL treatment regimen. Hypogonadism had been diagnosed in 20 patients $(41 \%)$; six of them $(30 \%)$ were noncompliant with testosterone replacement therapy. None of the patients had GH or other hormonal deficiencies diagnosed apart from hypogonadism.

The median age of the 55 control males was 30 years (range 24-36 years). The ALL survivors were shorter than the controls (median 177.0 vs $180.5 \mathrm{~cm}$; $P=0.007)$ but their weights $(78.9$ vs $82.8 \mathrm{~kg})$ and BMIs $\left(25.2\right.$ vs $\left.25.3 \mathrm{~kg} / \mathrm{m}^{2}\right)$ were similar $(P>0.05)$ (Table 2). The ALL subjects with a history of CNS irradiation $(n=36)$ were shorter $(P=0.003)$ than ALL
Table 1 Characteristics of the 49 male long-term ALL survivors.

\begin{tabular}{|c|c|c|c|}
\hline Characteristics & $\begin{array}{l}\text { Median } \\
\text { (range) }\end{array}$ & $n$ & $\begin{array}{c}\text { Survivors } \\
(\%)\end{array}$ \\
\hline Age at study (years) & $29(25-38)$ & & \\
\hline Age at diagnosis (years) & $5(1-15)$ & & \\
\hline$<5$ & & 23 & 47 \\
\hline $5-10$ & & 16 & 33 \\
\hline$>10$ & & 10 & 20 \\
\hline Age at end of therapy (years) & $8(3-17)$ & & \\
\hline$<5$ & & 2 & 4 \\
\hline $5-10$ & & 32 & 65 \\
\hline$>10$ & & 15 & 31 \\
\hline Time since end of therapy (years) & $20(10-29)$ & & \\
\hline $10-15$ & & 11 & 22 \\
\hline $16-20$ & & 15 & 31 \\
\hline $21-30$ & & 23 & 47 \\
\hline CNS irradiation (Gy) & & 36 & 73 \\
\hline 18 & & 5 & \\
\hline $24-26$ & & 30 & \\
\hline 48 & & 1 & \\
\hline Spinal irradiation 6 Gy & & 1 & 2 \\
\hline Testicular irradiation (Gy) & & 17 & 35 \\
\hline 10 & & 2 & \\
\hline 24 & & 15 & \\
\hline Cyclophosphamide $\left(\mathrm{g} / \mathrm{m}^{2}\right)$ & & 24 & 49 \\
\hline $1.2-3.0$ & & 7 & \\
\hline $4.6-9.9$ & & 13 & \\
\hline $25.0-29.0$ & & 4 & \\
\hline Diagnosis of hypogonadism & & 20 & 41 \\
\hline On replacement & & 14 & \\
\hline No replacement & & 6 & \\
\hline
\end{tabular}

males without CNS irradiation, whose heights were not different from the control males.

The ALL survivors were less active than the controls (mean physical training 0.9 vs $2.0 \mathrm{~h} /$ week; $P<0.001$ ) and spent more time watching $\mathrm{TV}$ and videos (on average 3.0 vs $2.1 \mathrm{~h} /$ day; $P=0.005$ ).

\section{Biochemistry}

There were significant differences between the ALL and control males in hormonal parameters and testicular function, as reported previously (4). The ALL males had higher FSH levels, lower testosterone levels, and lower inhibin-B levels (Table 3). Serum testosterone was below $7.0 \mathrm{nmol} / \mathrm{l}$ in six ALL males and in none of the controls. Serum IGF1 levels were similar but IGFBP3 levels were lower in the ALL survivors $(P<0.001)$.

Vitamin D status was poorer in the ALL subjects than in the controls (median S-25-OHD values 42 vs $48 \mathrm{nmol} / \mathrm{l} ; \mathrm{P}=0.001$; Table 3 ). This was partly due to seasonal variation as more control subjects (55\%) than ALL males (6\%) were assessed during the four summer months. When only S-25-OHD values obtained between September and May were included, the ALL patients still had inferior vitamin D levels (median 43 and $47 \mathrm{nmol} / \mathrm{l}$; $P=0.045)$. Altogether, $76 \%$ of the ALL males and $47 \%$ of the controls were determined as vitamin $\mathrm{D}$ deficient (S-25-OHD < $50 \mathrm{nmol} / \mathrm{l})$. PTH levels did not differ and only one ALL and three control males had supranormal 
Table 2 Anthropometry and bone densitometry findings in the 49 male ALL survivors and 55 healthy controls. $P$ values are given for unadjusted differences between the groups. After adjusting for height and S-25-OHD, all differences between the DXA-derived values became insignificant between the patients and controls except whole-body BMC and BMD.

\begin{tabular}{|c|c|c|c|c|c|}
\hline \multirow[b]{2}{*}{ Characteristics } & \multicolumn{2}{|c|}{ ALL survivors } & \multicolumn{2}{|c|}{ Controls } & \multirow[b]{2}{*}{$P$ value } \\
\hline & Median & Range & Median & Range & \\
\hline Age (years) & 29 & $25-38$ & 30 & $24-36$ & 0.22 \\
\hline Height $(\mathrm{cm})$ & 176.0 & $163.0-193.5$ & 180.0 & $167.5-194.0$ & 0.007 \\
\hline Weight (kg) & 75.5 & $48.5-118.0$ & 82.0 & $58.0-114.0$ & 0.099 \\
\hline BMI $\left(\mathrm{kg} / \mathrm{m}^{2}\right)$ & 24.3 & $18.3-35.9$ & 25.1 & $19.4-34.8$ & 0.467 \\
\hline \multicolumn{6}{|l|}{ Lumbar spine } \\
\hline $\mathrm{BMC}(\mathrm{g})$ & 67.6 & $47.2-107.84$ & 73.13 & $49.13-97.21$ & 0.014 \\
\hline BMD (Z-score) & -0.65 & $-3.1-+3.6$ & -0.20 & $-2.7-+3.0$ & 0.12 \\
\hline BMAD $\left(\mathrm{g} / \mathrm{cm}^{3}\right)$ & 0.126 & $0.093-0.174$ & 0.127 & $0.094-0.173$ & 0.33 \\
\hline \multicolumn{6}{|l|}{ Femoral neck } \\
\hline $\mathrm{BMC}(\mathrm{g})$ & 4.92 & $3.23-7.27$ & 5.35 & $3.62-7.28$ & 0.054 \\
\hline BMD (Z-score) & -0.30 & $-2.2-+1.7$ & -0.20 & $-1.9-+1.9$ & 0.066 \\
\hline \multicolumn{6}{|l|}{ Total hip } \\
\hline BMC (g) & 43.66 & $24.26-66.74$ & 45.8 & $29.41-69.73$ & 0.073 \\
\hline BMD (Z-score) & -0.20 & $-2.1-+2.1$ & 0.30 & $-1.4-+2.0$ & 0.055 \\
\hline \multicolumn{6}{|l|}{ Whole body } \\
\hline $\mathrm{BMC}(\mathrm{g})$ & 2503 & 1707-3702 & 2807 & 1952-3434 & $<0.001^{a}$ \\
\hline BMD (Z-score) & -1.0 & $-2.3-+2.2$ & 0.10 & $-1.6-+2.0$ & $<0.001^{a}$ \\
\hline
\end{tabular}

$\mathrm{BMC}$, bone mineral content; BMD, bone mineral density; BMAD, bone mineral apparent density.

${ }^{a}$ The differences remained significant also after adjusting for height and S-25-OHD.

(>73 ng/l) PTH values. However, S-Pi values (normal range $0.71-1.23 \mathrm{mmol} / \mathrm{l})$ were significantly lower in the ALL males $(P=0.004)$; six $(12 \%)$ ALL males and none of the controls had hypophosphatemia with S-Pi below $0.60 \mathrm{mmol} / \mathrm{l}$. These very low S-Pi levels did not associate with supranormal PTH or with cumulative methotrexate or cyclophosphamide. S-Ca levels (normal range $2.15-2.51 \mathrm{mmol} / \mathrm{l}$ ) were higher in the ALL males than in the controls (median 2.38 vs $2.33 \mathrm{mmol} / \mathrm{l}$; $P=0.046$ ).

\section{DXA findings}

The bone densitometry findings are presented in Table 2 and Fig. 1. The BMD Z-score values in the ALL survivors differed significantly from the expected mean value
(Z-score 0) in lumbar spine (mean Z-score -0.64 ; $P<0.001$ ), femoral neck (mean -0.33; $P=0.017$ ), and whole body (mean $-0.75 ; P<0.001$ ). In contrast, the respective mean Z-score values in the controls $(-0.27,0.00$, and $+0.61 ; P>0.1$ for all $)$ were normal. When compared with the healthy controls, the ALL survivors had significantly lower BMC values in lumbar spine $(P=0.014)$ and whole body $(P<0.001)$, and a similar trend was seen in femoral neck $(P=0.054)$ and total hip $(P=0.073)$. Similarly, BMD Z-scores were lower at all measured sites, but the difference reached statistical significance only for the whole-body BMD Z-score, which was significantly lower in the ALL survivors $(P<0.001)$. Altogether, four ALL males and three control males fulfilled the DXA criteria for osteoporosis (T-score $\leq-2.5$ ).

Table 3 Biochemical findings in the 49 ALL survivors and 55 controls.

\begin{tabular}{|c|c|c|c|c|c|}
\hline \multirow[b]{2}{*}{ Parameter } & \multicolumn{2}{|c|}{ ALL survivors } & \multicolumn{2}{|c|}{ Controls } & \multirow[b]{2}{*}{$P$ value } \\
\hline & Median & Range & Median & Range & \\
\hline $\mathrm{Ca}(\mathrm{mmol} / \mathrm{l})$ & 2.38 & $2.19-2.55$ & 2.33 & $2.11-2.58$ & 0.046 \\
\hline $\mathrm{Pi}(\mathrm{mmol} / \mathrm{l})$ & 0.87 & $0.41-1.41$ & 0.98 & $0.62-1.42$ & 0.004 \\
\hline ALP (U/I) & 69.0 & $23-119$ & 65 & $41-133$ & 0.23 \\
\hline PTH (ng/l) & 36 & $15-78$ & 36 & $11-130$ & 0.74 \\
\hline 25-OHD (nmol/l) & 42 & $20-76$ & 48 & $24-90$ & 0.001 \\
\hline Testosterone (nmol/l) & 14.5 & $0.40-61.8$ & 18.5 & $7.1-32.6$ & 0.001 \\
\hline Estradiol (nmol/l) & 0.08 & $0.03-0.27$ & 0.07 & $0.05-0.25$ & 0.27 \\
\hline Inhibin-B (ng/l) & 71 & $10-287$ & 158 & $74-307$ & $<0.001$ \\
\hline $\mathrm{FSH}$ & 5.0 & $0.9-55.5$ & 3.2 & $0.9-11.4$ & 0.002 \\
\hline LH & 4.2 & $0.0-22.8$ & 3.3 & $1.8-8.1$ & 0.084 \\
\hline IGF1 (nmol/l) & 23 & $6-49$ & 23 & $12-36$ & 0.87 \\
\hline IGFBP3 (mg/l) & 3.2 & $2.3-5.0$ & 4.3 & $3.1-6.1$ & $<0.001$ \\
\hline
\end{tabular}

$P$ values refer to the difference between ALL survivors and controls. Statistically significant $P$ values are marked in bold. 


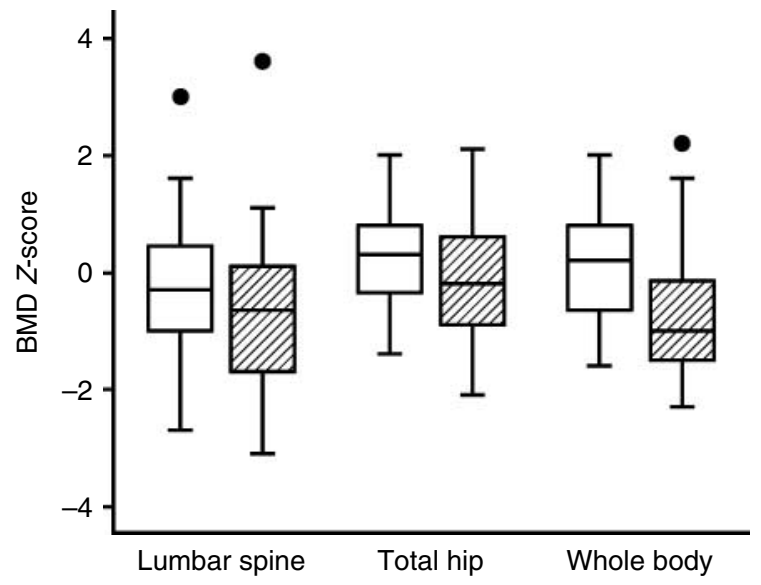

Figure 1 BMD Z-scores were lower in ALL survivors at all measured sites but the difference between the ALL survivors and controls reached statistical significance only for the whole-body BMD $Z$-score, which was significantly lower in the ALL survivors $(P<0.001)$. Controls, open bars; ALL survivors, shaded bars. The bottom of each box indicates the 25th, the cross line the 50th (median), and the top the 75th percentile of the variables. Whiskers extend to the minimum and the maximum. Outliers are shown as black circles.

All DXA parameters correlated significantly with each other. In the ALL males, S-25-OHD significantly associated with BMD at lumbar spine $(P=0.033)$, total hip $(P=0.018)$, and whole body $(P=0.015)$ while no such correlation was observed in the controls. IGFBP3 did not correlate with any of the DXA parameters in ALL or control males. Height and BMI also influenced BMD findings. Lumbar spine BMD Z-score in ALL subjects correlated significantly with weight $(P<0.001)$ and BMI $(P=0.006)$. When the DXA-derived values were adjusted for height and S-25-OHD, the differences between the groups still remained significant in whole-body BMC and BMD Z-score, the ALL males having lower values, while the other differences became insignificant (Table 2).

In ALL males, a lumbar spine BMD Z-score $<-1.0$ (present in $38 \%$ of the males) associated only with lower weight $(P=0.006)$ and BMI $(P=0.011)$ and low wholebody BMD Z-score (present in $48 \%$ ) only with lower height $(P=0.001)$ and weight $(P=0.002)$ compared with ALL males with higher BMD Z-score, and not with any hormonal, biochemical, or treatment-related parameters. In ALL males, physical activity and time spent watching TV did not correlate with any of the BMD parameters. In the control males, but not in the ALL males, the lumbar spine and total hip BMD Z-scores correlated inversely with S-inhibin-B values $(r=-0.34$, $P=0.017$ and $r=-0.38, P=0.006$ ).

Age at ALL diagnosis impacted on skeletal findings. Patients with ALL diagnosis before age 5 years had lower lumbar spine area $(P=0.002)$ and BMC $(P=0.009)$, lower whole-body area $(P=0.031)$, BMC $(P=0.009)$, BMD $T$-score $(P=0.015)$, and Z-score
$(P=0.013)$. These patients were also shorter $(174.7$ vs $179.1 \mathrm{~cm} ; P=0.036$ ).

ALL males with a history of CNS irradiation $(n=35)$ did not differ in any of the densitometric parameters from those with no CNS irradiation except for lumbar spine area, which was smaller in those with irradiation $(P=0.044)$, most likely reflecting their lower height. Further, patients who had received testicular irradiation and/or high-dose cyclophosphamide $\left(>20 \mathrm{~g} / \mathrm{m}^{2}\right.$; $n=21$ ) did not differ from the other ALL males in any DXA-related parameters $(P>0.1$ for all). When only patients with testicular irradiation $(n=17)$ were compared with the other ALL survivors, the BMD Zscores were similar $(P>0.05)$ and the only significant difference was smaller proximal femoral bone area in those with testicular irradiation $(P=0.029)$.

\section{Compression fractures}

Compression fractures were prevalent not only in ALL survivors $(20 \%)$ but also in the controls $(22 \%)$. The location and severity of the compression fractures along the spine was similar in both groups, most of the fractures being located in the lower half of the thoracic spine. When comparing the ALL subjects with $(n=10)$ and without $(n=39)$ compression fractures, none of the DXA parameters, biochemical parameters, or ALL treatment-related parameters differed, but those with compression fractures had higher BMI than subjects without compression fractures $\left(28.5\right.$ vs $24.5 \mathrm{~kg} / \mathrm{m}^{2}$; $P=0.024)$. In the controls, none of the DXA parameters, biochemical parameters, or clinical characteristics differed between those with $(n=12)$ and without $(n=43)$ compression fractures.

\section{Discussion}

We carried out a cross-sectional study to evaluate bone health and its clinical and biochemical determinants in long-term male ALL survivors at young adult age (25-38 years) and on average 20 years after the end of ALL therapy. The bone mass and BMD parameters were lower in the 49 ALL males than in the 55 age-matched control males without a history of cancer, and in the ALL survivors, these parameters differed significantly from the normative data. Altogether, $20 \%$ of the ALL males had spinal compression fractures but these were equally prevalent $(22 \%)$ also in the controls. Several potential risk factors for compromised bone health were identified in the adult male ALL survivors.

The BMD Z-score values in the ALL males were significantly lower than normative data while the values in the controls were normal. However, most of the differences between the survivors and controls were caused by reduced adult height (on average $4 \mathrm{~cm}$ ) in the ALL survivors. Especially, the subjects with previous CNS irradiation and/or ALL diagnosis before age 5 years 
tended to be shorter. As DXA gives a two-dimensional measurement of three-dimensional bones, persons with smaller bones will falsely have lower areal BMD despite identical volumetric bone densities (22). However, not all differences in densitometric findings between the groups disappeared when height and S-25-OHD were taken into account. Our findings indicate that long-term survivors of childhood ALL have an increased risk of low bone mass and consequently of fractures in adulthood.

To our knowledge, this is the first study to assess spinal morphology in long-term ALL survivors. We observed a significant number of compression fractures in the survivors: altogether, ten males $(20 \%)$ were found to have spinal compression fractures, mostly located in the lower half of the thoracic spine. We were not able to identify any clinical, biochemical, or ALL treatmentrelated risk factors for compression fractures, and the timing of these fractures remains unknown. Furthermore, the BMD findings were not different in the subjects with and without compression fractures.

Surprisingly, an equally large proportion of the control males had spinal compression fractures. The prevalence in the general young adult male population in Finland remains unknown. However, in our previous study, the prevalence of compression fractures in another control group $(n=138$, mean age 23 years, $55 \%$ males), assessed similarly as in this study, was only $5.1 \%$ (23). In another study on 158 healthy adults (median age 32.6 years; 76 males), we found compression fractures in none of the subjects (24). The high prevalence in our present controls may be due to recruitment bias. The controls, who were invited to a study assessing testicular function and fertility, had also lower sperm counts than healthy average Finnish males (4). The skeletal changes may reflect compromised gonadal function, although none of the controls had hypogonadism. The relationship between testicular function and bone health has proved to be much more complex than previously thought, and recent studies suggest that a bone-specific protein, osteocalcin, directly influences testosterone production by the Leydig cells in the testis (25). Based on these observations, it is possible that males who volunteer to studies related to testicular function are not optimal controls for bone health studies.

ALL may predispose to compression fractures by several mechanisms. Halton et al. (26) reported 16\% prevalence of vertebral compressions in newly diagnosed children with ALL who were assessed with spinal radiography within 30 days of ALL diagnosis. The ALL treatment itself with cytotoxic agents, impaired nutrition, and reduced physical activity has detrimental effects on bone mass. Furthermore, the potential endocrine sequelae, including GH deficiency and hypogonadism, impair bone mass development during the adolescent years. Although the prevalence of compression fractures in our ALL males was not different from the controls, the $20 \%$ prevalence is significantly higher than expected in the normal population and warrants close follow-up of ALL-treated subjects to detect early signs of osteoporosis.

When searching for clinical and treatment-related risk factors for low BMD and compression fractures in the ALL survivors, we were not able to show any differences in the skeletal characteristics, apart from height, in those with or without CNS irradiation, testicular irradiation, and/or cyclophosphamide. However, those diagnosed with ALL before age 5 years had significantly lower BMD values, suggesting that young children may be especially vulnerable to skeletal adverse effects. On the other hand, age of ALL diagnosis was similar in those with and without spinal compression fractures.

Several other potential risk factors for skeletal health were recognized among the survivors. Altogether, 20 ALL males had been diagnosed with hypogonadism. Most of them were on proper replacement therapy, but six males (12\% of the cohort) had untreated hypogonadism. Low S-Pi levels, not secondary to hyperparathyroidism, were observed in several subjects. These may be a consequence of renal tubular damage due to cytotoxic agents, although no correlation with cumulative methotrexate or cyclophosphamide doses were observed; renal tubular phosphate reabsorption was not evaluated. Further, the ALL subjects had lower IGFBP 3 levels but their IGF1 levels were similar to the controls. This may reflect inferior GH status in the ALL survivors (27). Altogether, 31 ALL subjects had received 24-48 Gy cranial irradiation, and this poses a significant risk for subsequent development of GH deficiency. Serum testosterone, $\mathrm{Pi}$, or IGFBP3 values did not correlate with any of the DXA-derived bone parameters and it thus remains unknown how these risk factors may influence bone health in ALL survivors during their later adulthood. Male hypogonadism is a significant risk factor for osteoporosis (28). It is important to ensure proper replacement therapy and follow the compliance in adult ALL survivors. Hypophosphatemia results in osteomalacia and in compromised bone quality over time.

Three quarters of the ALL subjects and half of the controls were vitamin D deficient (S-25-OHD $<50 \mathrm{nmol} / \mathrm{l}$ ). We have previously shown in several other cohorts that vitamin D deficiency is alarmingly common in all age groups in Finland $(23,29,30,31,32)$. The findings in the present cohort are in line with these observations. Unfortunately, the study assessments in the ALL males took place mostly during the winter months when vitamin D levels are lowest while more than half of the controls were assessed during the summer months. This bias prevented reliable comparison of the vitamin D status in the study groups. However, when values obtained outside the summer season were compared, the ALL males still had lower values. They also had less physical activity and spent more time watching TV, which in addition to being a 
risk factor for vitamin $\mathrm{D}$ deficiency is in itself a risk factor for compromised bone health. In the study by Tylavsky et al. (33), $<30 \%$ of 164 childhood ALL survivors (92 adults) met recommended dietary intakes for vitamin D, calcium, potassium, or magnesium. These dietary and other lifestyle factors may play a significant role in determining long-term skeletal and overall health in ALL survivors.

Our study suffers from some limitations. We did not collect detailed data on fracture history or lifestyle factors related to bone health (calcium and vitamin D intake, quality of physical activity) as the main focus of the study was on testicular function and fertility (4). BMD was quantified only with DXA and the results were thus significantly impacted by body size. These methodological limitations may have prevented us from identifying all differences between the patient and control groups and treatment-related differences within the ALL group. More accurate methods, such as peripheral quantitative CT should be considered in future studies. No Finnish reference values for this DXA equipment are available. We have previously tested the validity of the equipment-specific reference values for USA Caucasians in a cohort of 199 healthy Finnish children (age range 7.4-18.8 years, median 13.1 years); their median BMD Z-scores were 0.0, +0.1 , and 0.0 at the lumbar spine, total hip, and whole body respectively (34), suggesting that the USA Caucasian reference values are appropriate for the Finns. Therefore, it is unlikely that the reference values used in this study would cause a major bias in the results. The high prevalence of compression fractures in the control group suggests that the controls were not representative of the general population.

In conclusion, our study shows that at young adulthood (mean age 29 years), long-term male ALL survivors have significantly lower BMD values when compared with the general population. Reduced adult height, seen especially in those with a history of CNS irradiation or ALL diagnosis before age 5 years, may partly explain these reductions. The spinal compression fractures are likely to reflect abnormal bone quality. We recognized several potential risk factors for osteoporosis during adult life, including inadequately treated hypogonadism, vitamin D deficiency, hypophosphatemia, low IGFBP3, and low physical activity. These risk factors should be targeted to prevent skeletal complications during ALL treatment and follow-up.

\section{Declaration of interest}

The authors declare that there is no conflict of interest that could be perceived as prejudicing the impartiality of the research reported.

\section{Funding}

This study was supported by grants from the Swedish Barncancerfonden, the Finnish Cancer Society, the Finnish Pediatric Research Foundation, the Nona and Kullervo Väre Foundation, the Sigrid
Juselius Foundation, the Folkhälsan Research Foundation, the Academy of Finland, and the Helsinki University Hospital Research Funds.

\section{Acknowledgements}

The authors would like to thank Dr Jukka-Pekka Puutio and Prof. Martti Siimes for their contributions in initiating this study.

\section{References}

1 Mariotto AB, Rowland JH, Yabroff KR, Scoppa S, Hachey M, Ries L \& Feuer EJ. Long-term survivors of childhood cancers in the United States. Cancer Epidemiology, Biomarkers \& Prevention 200918 1033-1040. (doi:10.1158/1055-9965.EPI-08-0988)

2 Geenen MM, Cardous-Ubbink MC, Kremer LC, van den Bos C, van der Pal HJ, Heinen RC, Jaspers MW, Koning CC, Oldenburger F, Langeveld NE et al. Medical assessment of adverse health outcomes in long-term survivors of childhood cancer. Journal of the American Medical Association 2007297 2705-2715. (doi:10.1001/jama. 297.24.2705)

3 Steffens M, Beauloye V, Brichard B, Robert A, Alexopoulou O, Vermylen Ch \& Maiter D. Endocrine and metabolic disorders in young adult survivors of childhood acute lymphoblastic leukaemia (ALL) or non-Hodgkin lymphoma (NHL). Clinical Endocrinology 200869 819-827. (doi:10.1111/j.1365-2265.2008.03283.x)

4 Jahnukainen K, Heikkinen R, Henriksson M, Cooper TG, Puukko-Viertomies LR \& Mäkitie O. Semen quality and fertility in adult long-term survivors of childhood acute lymphoblastic leukemia. Fertility and Sterility 201196 837-842. (doi:10.1016/j. fertnstert.2011.07.1147)

5 Steinberger J, Sinaiko AR, Kelly AS, Leisenring WM, Steffen LM, Goodman P, Mulrooney DA, Dietz AC, Moran A, Perkins JL et al. Cardiovascular risk and insulin resistance in childhood cancer survivors. Journal of Pediatrics 2012160 494-499. (doi:10.1016/ j.jpeds.2011.08.018)

6 Oudin C, Simeoni MC, Sirvent N, Contet A, Begu-Le Coroller A, Bordigoni P, Curtillet C, Poirée M, Thuret I, Play B et al. Prevalence and risk factors of the metabolic syndrome in adult survivors of childhood leukemia. Blood 2011117 4442-4448. (doi:10.1182/ blood-2010-09-304899)

7 Arikoski P, Komulainen J, Voutilainen R, Riikonen P, Parviainen M, Tapanainen P, Knip M \& Kroger H. Reduced bone mineral density in long-term survivors of childhood acute lymphoblastic leukemia. Journal of Pediatric Hematology/Oncology $1998 \quad 20 \quad 234-240$. (doi:10.1097/00043426-199805000-00009)

8 Halton JM, Atkinson SA, Fraher L, Webber CE, Cockshott WP, Tam C \& Barr RD. Mineral homeostasis and bone mass at diagnosis in children with acute lymphoblastic leukemia. Journal of Pediatrics 1995126 557-564. (doi:10.1016/S0022-3476(95)70349-7)

9 Hoorweg-Nijman JJ, Kardos G, Roos JC, van Dijk HJ, Netelenbos C, Popp-Snijders C, de Ridder CM \& Delemarre-van de Waal HA. Bone mineral density and markers of bone turnover in young adult survivors of childhood lymphoblastic leukaemia. Clinical Endocrinology 199950 237-244. (doi:10.1046/j.1365-2265.1999. 00654.x)

10 Thomas IH, Donohue JE, Ness KK, Dengel DR, Baker KS \& Gurney JG. Bone mineral density in young adult survivors of acute lymphoblastic leukemia. Cancer $2008 \quad 113$ 3248-3256. (doi:10.1002/cncr.23912)

11 Follin C, Link K, Wiebe T, Moëll C, Björk J \& Erfurth EM. Bone loss after childhood acute lymphoblastic leukaemia: an observational study with and without GH therapy. European Journal of Endocrinology 2011164 695-703. (doi:10.1530/EJE-10-1075)

12 Le Meignen M, Auquier P, Barlogis V, Sirvent N, Contet A, Simeoni MC, Galambrun C, Poirée M, Chastagner P, Play B et al. Bone mineral density in adult survivors of childhood acute 
leukemia: impact of hematopoietic stem cell transplantation and other treatment modalities. Blood 2011118 1481-1489. (doi:10.1182/blood-2011-01-332866)

13 Cummings SR, Black DM, Nevitt MC, Browner W, Cauley J, Ensrud K, Genant HK, Palermo L, Scott J \& Vogt TM. Bone density at various sites for prediction of hip fractures. The Study of Osteoporotic Fractures Research Group. Lancet 1993341 72-75. (doi:10.1016/0140-6736(93)92555-8)

14 Theintz G, Buchs B, Rizzoli R, Slosman D, Clavien H, Sizonenko PC \& Bonjour JP. Longitudinal monitoring of bone mass accumulation in healthy adolescents: evidence for a marked reduction after 16 years of age at the levels of lumbar spine and femoral neck in female subjects. Journal of Clinical Endocrinology and Metabolism 199275 1060-1065. (doi:10.1210/jc.75.4.1060)

15 Matkovic V, Jelic T, Wardlaw GM, Ilich JZ, Goel PK, Wright JK, Andon MB, Smith KT \& Heaney RP. Timing of peak bone mass in Caucasian females and its implication for the prevention of osteoporosis. Inference from a cross-sectional model. Journal of Clinical Investigation 199493 799-808. (doi:10.1172/JCI117034)

16 Javaid MK \& Cooper C. Prenatal and childhood influences on osteoporosis. Best Practice \& Research. Clinical Endocrinology \& Metabolism 200216 349-367. (doi:10.1053/beem.2002.0199)

17 Sorva R, Lankinen S, Tolppanen EM \& Perheentupa J. Variation of growth in height and weight of children. II. After infancy. Acta Paediatrica Scandinavica 199079 498-506. (doi:10.1111/j.16512227.1990.tb11503.x)

18 Pere A. Comparison of two methods for transforming height and weight to normality. Annals of Human Biology 200027 35-45. (doi:10.1080/030144600282361)

19 Kanis JA, Melton LJ III, Christiansen C, Johnston CC \& Khaltaev N. The diagnosis of osteoporosis. Journal of Bone and Mineral Research 19949 1137-1141. (doi:10.1002/jbmr.5650090802)

20 Carter DR, Bouxsein ML \& Marcus R. New approaches for interpreting projected bone densitometry data. Journal of Bone and Mineral Research 19927 137-145. (doi:10.1002/jbmr. 5650070204)

21 Genant HK, Wu CY, van Kuijk C \& Nevitt MC. Vertebral fracture assessment using a semiquantitative technique. Journal of Bone and Mineral Research 19938 1137-1148. (doi:10.1002/jbmr. 5650080915)

22 Leonard MB. Assessment of bone mass following renal transplantation in children. Pediatric Nephrology 200520 360-367. (doi:10.1007/s00467-004-1747-y)

23 Hovi P, Andersson S, Järvenpää AL, Eriksson JG, StrangKarlsson S, Kajantie E \& Mäkitie O. Decreased bone mineral density in adults born with very low birth weight: a cohort study. PLoS Medicine 20096 e1000135. (doi:10.1371/journal.pmed. 1000135)

24 Pirilä S, Taskinen M, Viljakainen H, Kajosaari M, Turanlahti M, Saarinen-Pihkala UM \& Mäkitie O. Infant milk feeding influences adult bone health: a prospective study from birth to 32 years. PLoS ONE 20116 e19068. (doi:10.1371/journal.pone.0019068)
25 Oury F, Sumara G, Sumara O, Ferron M, Chang H, Smith CE, Hermo L, Suarez S, Roth BL, Ducy P et al. Endocrine regulation of male fertility by the skeleton. Cell $2011 \mathbf{1 4 4} 796-809$. (doi:10.1016/j.cell.2011.02.004)

26 Halton J, Gaboury I, Grant R, Alos N, Cummings EA, Matzinger M, Shenouda N, Lentle B, Abish S, Atkinson S et al. Advanced vertebral fracture among newly diagnosed children with acute lymphoblastic leukemia: results of the Canadian Steroid-Associated Osteoporosis in the Pediatric Population (STOPP) research program. Journal of Bone and Mineral Research 200924 1326-1334. (doi:10.1359/ jbmr.090202)

27 Stanley T. Diagnosis of growth hormone deficiency in childhood. Current Opinion in Endocrinology, Diabetes, and Obesity 201219 47-52. (doi:10.1097/MED.0b013e32834ec952)

28 Bours SP, van Geel TA, Geusens PP, Janssen MJ, Janzing HM, Hoffland GA, Willems PC \& van den Bergh JP. Contributors to secondary osteoporosis and metabolic bone diseases in patients presenting with a clinical fracture. Journal of Clinical Endocrinology and Metabolism 201196 1360-1367. (doi:10.1210/jc.20102135)

29 Kilpinen-Loisa P, Arvio M, Ilvesmäki V \& Mäkitie O. Vitamin D status and optimal supplementation in institutionalized adults with intellectual disability. Journal of Intellectual Disability Research 2009 53 1014-1023. (doi:10.1111/j.1365-2788.2009.01218.x)

30 Kilpinen-Loisa P, Paasio T, Soiva M, Ritanen UM, Lautala P, Palmu P, Pihko H \& Mäkitie O. Low bone mass in patients with motor disability: prevalence and risk factors in 59 Finnish children. Developmental Medicine and Child Neurology 201052 276-282. (doi:10.1111/j.1469-8749.2009.03464.x)

31 Viljakainen HT, Pekkinen M, Saarnio E, Karp H, LambergAllardt C \& Mäkitie O. Dual effect of adipose tissue on bone health during growth. Bone 201148 212-217. (doi:10.1016/j.bone. 2010.09.022)

32 Viljakainen HT, Korhonen T, Hytinantti T, Laitinen EK, Andersson S, Mäkitie O \& Lamberg-Allardt C. Maternal vitamin D status affects bone growth in early childhood - a prospective cohort study. Osteoporosis International 201122 883-891. (doi:10.1007/s00198-010-1499-4)

33 Tylavsky FA, Smith K, Surprise H, Garland S, Yan X, McCammon E, Hudson MM, Pui CH \& Kaste SC. Nutritional intake of long-term survivors of childhood acute lymphoblastic leukemia: evidence for bone health interventional opportunities. Pediatric Blood \& Cancer 201055 1362-1369. (doi:10.1002/pbc. 22737)

34 Valta H, Mäkitie O, Rönnholm K \& Jalanko H. Bone health in children and adolescents after renal transplantation. Journal of Bone and Mineral Research 200924 1699-1708. (doi:10.1359/ jbmr.090407)

Received 14 August 2012

Revised version received 29 October 2012

Accepted 29 November 2012 